\title{
Use of Tandem Stents for Treatment of Helicoidal Dissection of the Right Coronary Artery
}

\author{
Murillo K. Furukawa, Carlos Eduardo M. Domingues, Marcos César V. de Almeida, \\ Virgílio Ribeiro Franco Jr, Décio Salvadori Jr
}

São Paulo, SP - Brazil

\begin{abstract}
Coronary dissection occurs frequently and in several degrees during coronary angioplasty, which is one of the mechanisms for increasing the lumen diameter of a vessel. However the length of the dissection may affect the procedure, becoming the most frequent cause of total occlusion after coronary angioplasty. We report here a case of extensive dissection that occurred during the coronary angioplasty of a focused lesion, which we treated with two long stents.
\end{abstract}

Coronary dissection is a frequent phenomenon during coronary angioplasty, the mechanical alteration of a vessel that increases luminal diameter. It may occur in several degrees of severity, from simple dissections with good evolution to more serious and complex ones that may lead to the occlusion of the artery being treated.

We report the case of a long and helicoidal dissection of a right coronary artery, with distal occlusion, treated by implantation of two long and tandem stents, with good results.

\section{Case Report}

The patient is a 60-year-old female admitted for investigation of recent angina, which evolved quickly to the occurrence of symptoms at rest. She previously had systemic arterial hypertension and light hypercholesterolemia.

She underwent cinecoronaryography on April 15, 1998, which showed subocclusion of the right coronary artery in the midthird section (fig. 1) and absence of significant lesions in the left coronary artery. The left ventricle had normal volumes and contraction. On April 17, 1998 the patient underwent angioplasty and implantation of a stent in the right coronary artery.

The procedure was carried out via the femoral artery with a JR 3.5 7F catheter guide (Cordis Corp. - Johnson \& Johnson Co.). The lesion was passed through without dif-

Hospital São Joaquim da Real e Benemérita Sociedade Portuguesa de Beneficência - São Paulo

Mailing address: Murillo K. Furukawa - Salvacor - Hemodinâmica e Card. Intervencionista - Hosp. Beneficência Portuguesa de São Paulo - Rua Maestro Cardim, 769 - $2^{\circ}$ S/solo - bloco IV - 01323-001 - São Paulo, SP - Brazil ficulty with a 0.014" Extra Sport guidewire (Guidant/Advanced Cardiovascular Systems), and the stent was distally placed in the posterior ventricular branch. Predilation followed, using a balloon catheter model Valor $3.5 \times 20 \mathrm{~mm}$ (Cordis Corp. - Johnson \& Johnson Co.) totally inflating the balloon with $5 \mathrm{~atm}$.

In subsequent angiography an image of a dissection at the treated spot was observed with no disruption to the flow of the contrast liquid (fig. 2); however, in the following moments the patient started to complain of strong precordial pain, associated with an important elevation of DII derivation in the ECG. With a new angiography, extensive dissection of the right coronary artery was noted, beginning at the location of the predilation and with distal occlusion (figs. 3 and 4). Attempts to "glue" the dissection with the same balloon catheter were made inclusively with prolonged insufflations at the location of the occlusion, however, unsuccessfully.

In view of this, our option was to place a stent in the midthird section, using a Crown Model 3.5x32mm (Cordis Corp.- Johnson \& Johnson Co.), which was expanded with $10 \mathrm{~atm}$ with no difficulty. On subsequent angiography, of the region was noted to be in good condition, however no improvement was noted in the distal portion. We decided on the placement of a second stent. Initially, the guidewire was manipulated in such a way as to anchor it to the posterior descending branch and afterwards we introduced a stent model Multilink 3.0x25mm (Guidant/Advanced Cardiovascular Systems), which was guided through the first stent and released in such a way that its distal extremity would remain immediately before the origin of that branch. This stent was also expanded with $10 \mathrm{~atm}$. The new control angiography showed excellent results (fig. 5).

The patient evolved satisfactorily reaching the maximum CKMB level of 7/U/L and was discharged 5 days later. Although the patient was asymptomatic, the ECG performed at discharge showed a chain of subendocardiac ischemia in the lower region, a phenomenon absent in the preangioplasty coronary records.

During ambulatory follow-up, the patient was free of angina, with a normal ECG and a stress test negative for ischemia. When the patient underwent control cinecoronariography on May 15, 1999, a moderate 50\% lesion was ob- 


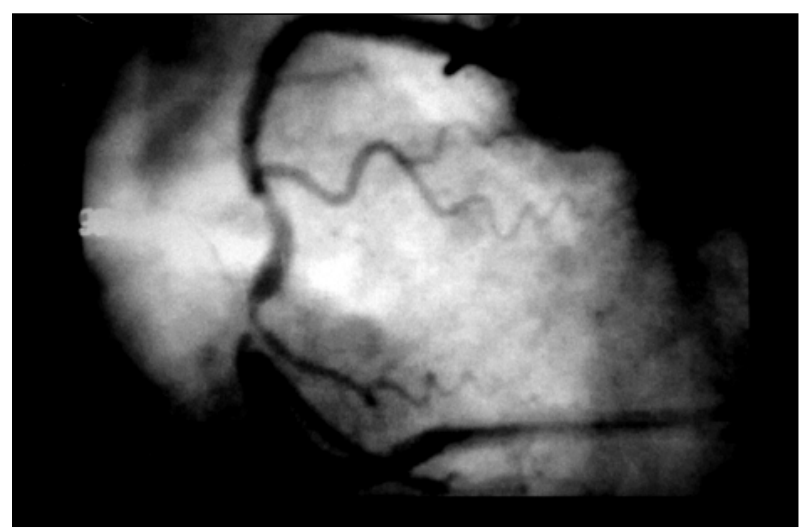

Fig. 1 - Right coronary - before coronary angioplasty.

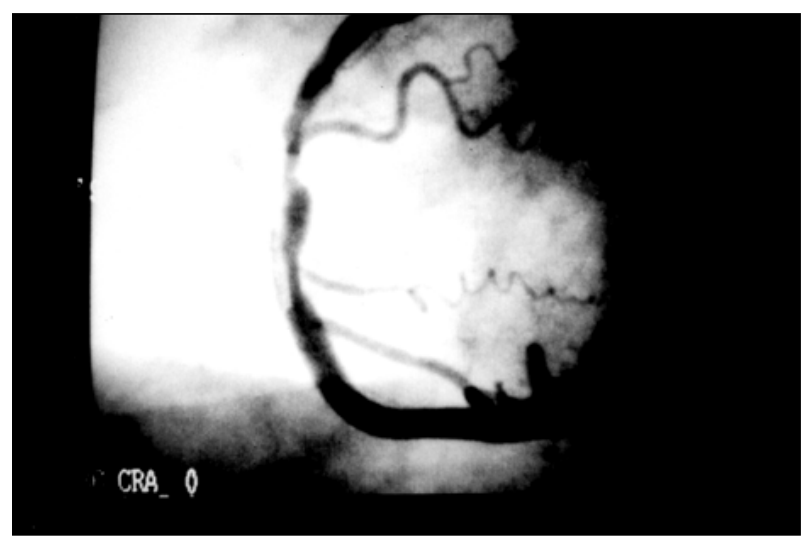

Fig. 2 - Aspect immediately after predilation.

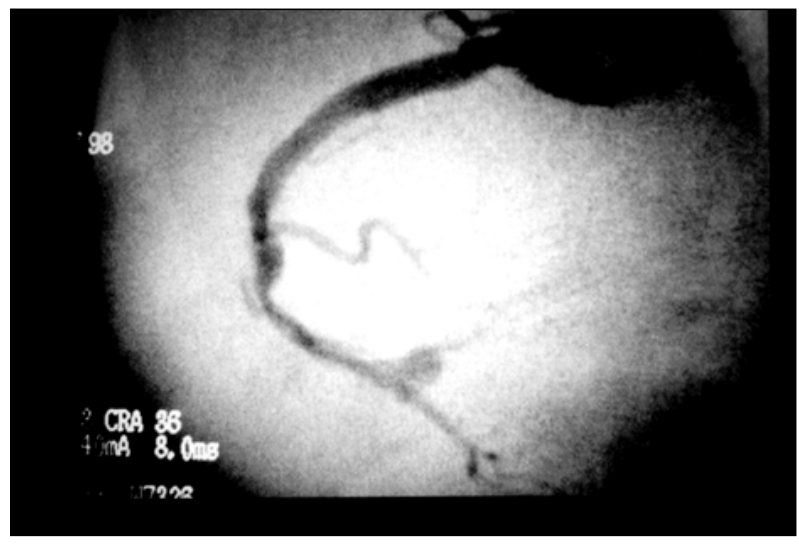

Fig. 3 - Presence of extensive dissection and distal occlusion.

served between the two stents (not the treated region), and good results were observed in the treated region (fig. 6).

\section{Discussion}

Coronary dissection is a phenomenon not only frequent, but part of balloon angioplasty, a mechanism for the enlargement of the internal diameter of a vessel treated as a result of the compression and break-down of atherosclerotic plaque in addition to the rupture of the endothelium itself. In

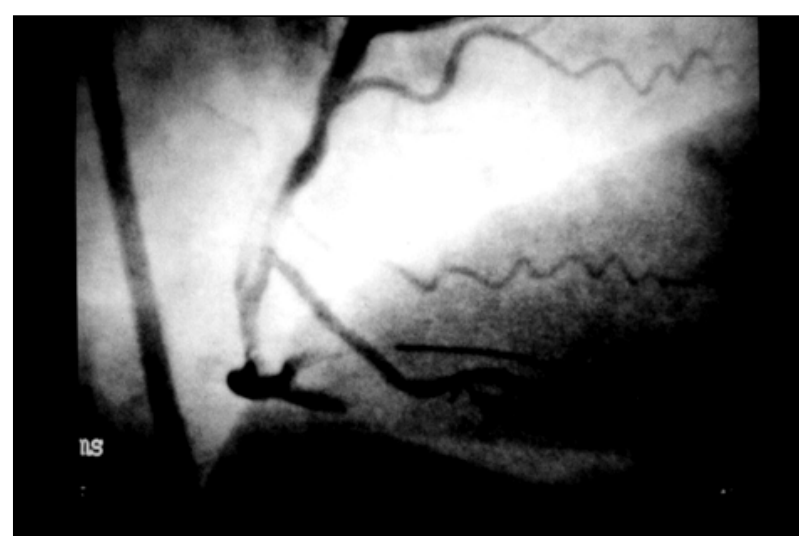

Fig. 4 - Clear dissection in the midthird and distal occlusion.

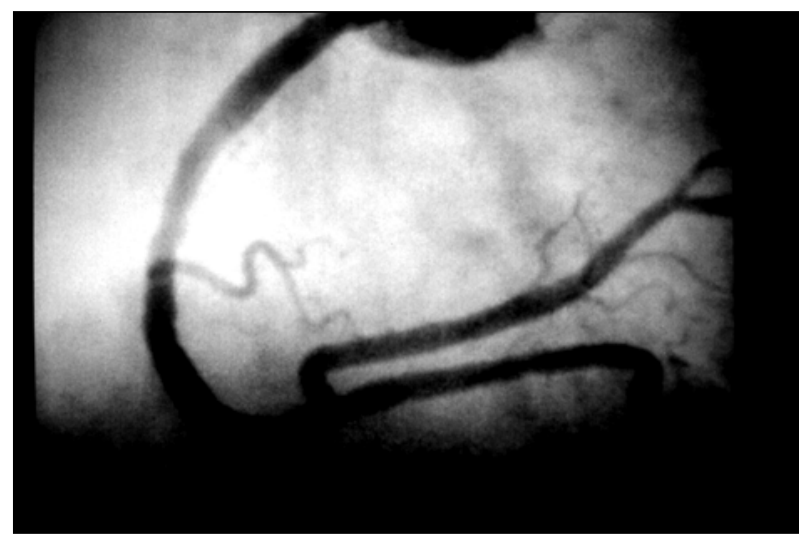

Fig. 5 - Final result after implantation of two stents.

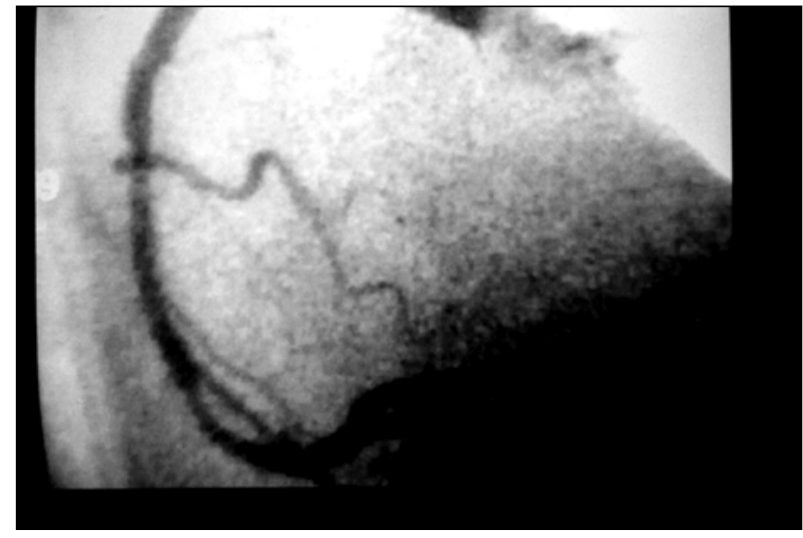

Fig. 6 - Angiography after a year.

most cases, dissection is not detected by angiography, being observed in only $20-40 \%$ of the cases ${ }^{1}$. But it can, however, be detected in 60 to $80 \%$ of the cases when intracoronary ultrasound or angioscopy ${ }^{2}$ is used. Its detection by angiography also varies according to the method employed, a lower incidence being verified when a stent is used $(<10 \%)$.

When visualized by angiography, the dissection is shown to occur in several different grades and can be classified from A to F, according to the NHLBI-National Heart, Lung and Blood Institute classifications (table I). A and B class 
Table I - Coronary dissection: NHLBI - National Heart, Lung and Blood Institute classification

\begin{tabular}{|cl|}
\hline Type & Description \\
\hline A & $\begin{array}{l}\text { Radiotransparent lines within the coronary artery during injection of } \\
\text { contrast liquid, with minimum persistence or absence after its outflow. }\end{array}$ \\
B $\quad \begin{array}{l}\text { Parallel lines or image of a double lumen separated by a radio- } \\
\text { transparent area during injection of contrast, with minimum } \\
\text { persistence or absence after its outflow. }\end{array}$ \\
C $\quad \begin{array}{l}\text { Extraluminal "cover" with persistence of contrast in place after } \\
\text { its outflow from the lumen of the vessel. }\end{array}$ \\
D $\quad \begin{array}{l}\text { Faulty filling in spiral } \\
\text { E* }\end{array}$ \\
Showing of new and faulty filling. \\
Those non-A - E types that lead to important diminishing of flow \\
or total occlusion.
\end{tabular}

dissections are considered to be slight or small dissections and apparently do not interfere in the performance of balloon angioplasty; however, $\mathrm{C}$ to $\mathrm{F}$ types are associated with a five times greater incidence of myocardial infarction, revascularization of the target lesion or death and are therefore considered serious or life-threatening dissections ${ }^{3}$. In the STRESS study ${ }^{3}$, which involved 410 patients, the presence of dissections resulted in a lower success rate of angioplasty (75\% versus $92 \%$ ) and a high rate of ischemic events during the hospitalization period $(15 \%$ versus $3 \%, \mathrm{p}<0.05)$.
When not resulting in ischemic alterations, the dissections tend to disappear spontaneously in time. Angiographic evaluations showed that 4 to $16 \%$ of the dissections disappeared in 24 hours, and 63 to $93 \%$ between 3-6 month ${ }^{4}$. Studies showed that dissections have no impact on restenosis ${ }^{4,5}$.

The occurrence of dissections in more complex lesions (very eccentric, long, calcified, diffused or curved) is greater and should guide the strategy of the treatment approach used.

The use of stents has greatly eased the handling of dissections, providing mechanical support for the dissected areas and even closing the dissection entrance. Therefore, stents have become a choice, an option for treatment, especially when the dissection is larger than the initially treated segment. De Scheerder et al used long stents $(>24 \mathrm{~mm})$ in 55 arteries and multiple short stents $(16 \mathrm{~mm})$ in another 60; fifty-one of the treated long dissections postangioplasty were successful in all cases, and in the six-month follow-up angiographic reevaluation, a general restenosis of $30 \%$ was documented between the two groups, without a statistical difference ${ }^{6}$.

In this report, we emphasize that the quality of the materials allowed the passage of one long stent $(25 \mathrm{~mm})$ into another long $(32 \mathrm{~mm})$ already implanted stent. This procedure also could be carried out due to the current availability of guidewires with excellent support and less rigid stents with a lower surface area.

\section{References}

1. Sharma SK, Israel DH, Kamean JL, Bodian CA. Clinical, angiographic and procedural determinants of major and minor coronary dissection during angioplasty. Am Heart J 1993; 126: 39-47.

2. den Heijer P, Foley D, Escaned J, Hillege H. Angioscopic versus angiographic detection of intimal dissection and intracoronary trombus. J Am Cardiol 1994; 24(3): 649-54.

3. Freed M, O'Neil WW, Safian RD. Dissection and Acute Closure. In: Freed M, Grines C, Safian RD, eds. The New Manual of Interventional Cardiology. Birminghan: Physician's Press, 1996: 369.
4. Cappelletti A, MargonatoA, Berna G, Chierchia S. Spontaneous evolution of nonoclusive coronary dissection after PTCA: a 6-month angiographic follow-up study. J Am Coll Cardiol 1995; 25: 345A.

5. Savage M, Dischman D, Bailey S, et al. Vascular remodeling of balloon-induced intimal dissection: long-term angiographic assessment. J Am Cardiol, 1995; 25: 139A.

6. De Scheerder IK, Wang K, Kostopoulos K, et al. Treatment of long dissections by use of a single long or multiple short stents: clinical and angiographic follow-up. Am Heart Journal, 1998; 136: 345-51. 